\title{
ations BRCA status assessment in epithelial ovarian \\ cancer and the challenge of tumor testing
}

${ }^{1}$ Department of Gynecologic Oncology, Fondazione Policlinico Universitario A. Gemelli, IRCCS, Rome, Italy

${ }^{2}$ Molecular and Genomics Diagnostics Unit, Fondazione Policlinico Universitario A. Gemelli, IRCCS, Rome, Italy ${ }^{3}$ Fondazione Policlinico Universitario, IRCCS, Rome, Italy ${ }^{4}$ Catholic University of the Sacred Heart, Rome, Italy

\section{Correspondence to}

Ms Anna Fagotti, Woman and Child's Health Department, Universita Cattolica del Sacro Cuore Facolta di Medicina e Chirurgia, Roma, Italy; annafagotti70@gmail.com

Received 27 May 2020 Revised 29 May 2020 Accepted 2 June 2020 Published Online First 4 August 2020
Check for updates

(C) IGCS and ESGO 2020. No commercial re-use. See rights and permissions. Published by BMJ.

\begin{tabular}{l}
\hline To cite: Marchetti C, \\
Minucci A, Pietragalla A, \\
et al. Int J Gynecol Cancer \\
2020;30:1465-1466.
\end{tabular}

Claudia Marchetti, ${ }^{1}$ Angelo Minucci, ${ }^{2}$ Antonella Pietragalla (D) , ${ }^{3}$ Giovanni Scambia, ${ }^{1,4}$ Anna Fagotti (D) 1,4

We read with great interest the recently published ASCO guidelines regarding the need for genomic testing in patients with epithelial ovarian cancer. ${ }^{1}$ The authors made a notable effort to further the field as it pertains to germline and somatic mutations in patients with epithelial ovarian cancer and to personalize its management. Nevertheless, we were rather surprised that women diagnosed with epithelial ovarian cancer should have germline $B R C A$ ( $g B R C A)$ genetic testing, while reserving tumor tissue DNA ( $t B R C A)$ sequencing only for those with negative $g B R C A$.

The authors stated that "up to $5 \%$ of germline mutations will be missed if using tumor somatic mutation results" and that "missing a germline mutation has grave implications for family members". Although we fully agree with the last sentence, we believe that some issues need to be discussed. The authors' reference to $5 \%$ of $g B R C A$ pathogenic variants in $t B R C A$ negative cases is taken from the SOL01 study, where all patients were either gBRCA or tBRCA mutants. ${ }^{2}$ Seventeen samples showed discordances; in particular, 12 of $341(3.5 \%)$ were $t B R C A$ wild-type and five $(1.5 \%)$ had a $t B R C A$ variant of unknown significance. If we do not consider a variant of unknown significance as tumor test missing, but rather as a different variant interpretation, we can conclude that $3.5 \%$ is the rate of missed germline pathogenic variants. This still seems a high value, due to the possible impact on missed cascade genetic screening.

In the SOL01 trial, formalin-fixed, paraffinembedded tissue was used for tBRCA testing. Formalin-fixed, paraffin-embedded quality, different DNA extraction protocols, and level of DNA integrity testing may influence the quality of the extracted DNA, muddying sequencing and subsequent analysis. ${ }^{3}$ More recently, fresh frozen tissue has been proposed as an alternative procedure. ${ }^{45}$ This tissue handling seems to minimize damage to nucleotides, allowing extraction of high-quality DNA, enabling the identification of $g B R C A$ large genomic rearrangements in tumor tissue. ${ }^{6}$ Indeed, 10 of 12 tBRCA wild-type samples were due to large genomic rearrangements, reported by Myriad test but not detected by Foundation Medicine Kit.
We admit that a fresh-frozen, tissue-based BRCA testing approach is not simple to offer, as it is strictly related to hospital organization, depending on close cooperation among surgeons, pathologists, and the molecular testing team. With this regard, in 456 patients with high-grade serous carcinoma, we found that commitment of all professionals enables freshfrozen, tissue-based $B R C A$ testing to identify up to $32 \%$ of patients with the $t B R C A$ mutation (including those with germline large genomic rearrangements), ruling out $6 \%$ of women who would have been missed if only gBRCA testing had been performed. ${ }^{7}$

Lastly, it remains unclear which is the most costeffective approach. ${ }^{8}$ According to the ASCO guidelines, ${ }^{1}$ all patients with epithelial ovarian cancer with no gBRCA mutation will require tumor testing to unmask the presence of a somatic mutation. If we assume approximately $20 \%$ of cases of high-grade serous epithelial ovarian cancer harbor a $g B R C A$ mutation, roughly $80 \%$ will undergo $t B R C A$ testing, with a $t B R C A$ mutation found in no more than $15 \%$ of cases. As a consequence, $65 \%$ of patients with epithelial ovarian cancer will receive a needless and expensive double-test procedure.

In our view, broadening of the BRCA-tested population should be pursued, while reducing expensive, unnecessary and stressful double-test procedures. If fresh tissue is the way, then we should persevere and improve our laboratory technical skills for BRCA testing interpretation, as well as our commitment toward an effective 'in-house 'BRCA testing approach.

\section{Twitter Anna Fagotti @annafagottimd}

Contributors All authors have read and approved the manuscript. All authors consistently contributed to the manuscript.

Funding The authors have not declared a specific grant for this research from any funding agency in the public, commercial or not-for-profit sectors.

Competing interests None declared.

Patient consent for publication Not required.

Provenance and peer review Not commissioned; internally peer reviewed.

\section{ORCID iDs}

Antonella Pietragalla http://orcid.org/0000-0001-6232-0323 Anna Fagotti http://orcid.org/0000-0001-5579-335X 


\section{Commentary}

\section{REFERENCES}

1 Konstantinopoulos PA, Norquist B, Lacchetti C, et al. Germline and somatic tumor testing in epithelial ovarian cancer: ASCO guideline. $J$ Clin Oncol 2020;38:1222-45.

2 Moore K, Colombo N, Scambia G, et al. Maintenance olaparib in patients with newly diagnosed advanced ovarian cancer. $N$ Engl J Med 2018;379:2495-505.

3 Mafficini A, Simbolo M, Parisi A, et al. BRCA somatic and germline mutation detection in paraffin embedded ovarian cancers by nextgeneration sequencing. Oncotarget 2016;7:1076-83.

4 Gori S, Barberis M, Bella MA, et al. Recommendations for the implementation of BRCA testing in ovarian cancer patients and their relatives. Crit Rev Oncol Hematol 2019;140:67-72.
5 Capoluongo E, Scambia G, Nabholtz J-M. Main implications related to the switch to $B R C A 1 / 2$ tumor testing in ovarian cancer patients: a proposal of a consensus. Oncotarget 2018;9:19463-8.

6 Minucci A, Mazzuccato G, Marchetti C, et al. Detecting germline rearrangements of BRCA1 by next generation tumor sequencing. $\mathrm{Mol}$ Biol 2020. In press.

7 D'Indinosante M, Marchetti C, Caricato C, et al. BRCA tumortesting in a tertiary referral center: are we missing something or not? Presented at the Society of Gynecologic Oncology's 51th Annual Meeting on Women's Cancer 2020.

8 Kwon JS, Tinker AV TA, Karsanc A, et al. Costs and benefits of tumor testing for BRCA mutations in high-grade serous ovarian cancer as a companion diagnostic for PARP inhibitor treatment. Presented at the Society of Gynecologic Oncology's 50th Annual Meeting on Women's Cancer. Honolulu, HI, 2019. 